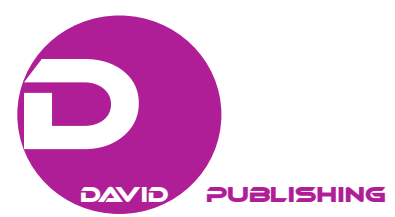

\title{
What Can Come out Controlling-A Chance for the Perfect Business Intelligence
}

\author{
György Fabricius-Ferke \\ Szent István University, Gödöllő, Hungary
}

\begin{abstract}
This paper claims that Controlling Systems are very close examples of a "perfect" artificial intelligence; they are legitimate business intelligence software. How can perfect artificial intelligence come from Controlling Systems - the following analysis is aimed at answering this very question. It is clear that the unique characteristics that their information systems have are playing an important part of improving the business intelligence system of the firm. The main areas of research interest are: the unique building blocks of the Controlling Systems of the enterprises (AIT-1, 2, and 3), the problem of how well the IT's system is integrated, the relation between accounting policy and the IT' data structure, and the role of strategic and operative time periods of controlling in the artificial intelligence systems of enterprises. The paper discusses the following issues: the unique existence of economic artificial intelligence, the evolution habit of IT intelligence system, and the control of management.
\end{abstract}

Keywords: business intelligence, artificial intelligence, controlling, business information systems, business IT, management information systems, management-IT

\section{Introduction}

The history of the Controlling began in 1930 in the USA. Its birth and development was partly influenced by the Great Depression. One can say that the core of Controlling is a regulatory principle that has been known in the engineering sciences for centuries, and is the basis of analogue computers. At the middle of the 1940's, John Neumann created the basis for using digital computers for accounting tasks (Neumann, 1959). Systems theory became known during the 1960's. This approach is important for a detailed approach to managing accounting systems, which makes implementing upgrades easier.

At the present day, the advances in electronics push the development of digital systems forward at an amazing speed. An example is how out grandchildren are able to navigate the entire world using a single finger and a smartphone. However, there remains a relevant question: in what areas and to what degree should one relinquish one's "leading" role to artificial intelligence systems?

The economies of the Central-Eastern European region have been on similar development paths than the Western World after the Great Depression - albeit, clearly, these paths are characterized by local idiosyncrasies. In the last quarter of the XX century, Hungary has gradually returned to a market economy model, and microeconomic agents (organizations) are gradually adopting the enterprise management techniques that characterize modern market economies - a prime example being the adoption of controlling systems.

György Fabricius-Ferke, doctorand, Institute of Finance \& Accounting, Szent István University, Gödöllö, Hungary.

Correspondence concerning this article should be addressed to György Fabricius-Ferke, 28 Ilona str. H-2030, Érd, Hungary. 
This paper presents the conclusions that can be drawn from the analysis of the development of the enterprise management systems of 24 Hungarian SMEs. Specifically, these conclusions relate to the use of controlling systems, and in more general terms, business intelligence systems. What kind of management functions can be automated in a microeconomic setting, and what are the rules and opportunities of business intelligence development? The analysis spans a 29 years period, and draws conclusions not simply from observations, but from the experiences of the implementation of different business intelligence modules. The analyzed companies include small and medium, as well as Hungarian-owned as well as internationally-owned enterprises. By the showing how the 24 SMEs changed and developed, one can show what the perfect artificial intelligence might look like.

\section{Controlling as a Feedback System}

One can present the Controlling system as a "CYBERMATICS" model (cybernetics + informatics). This model describes the process through which an enterprise or economic agent adapts to its business environment (Bertalanffy, 1962; Fabricius-Ferke, 2011; 2014):

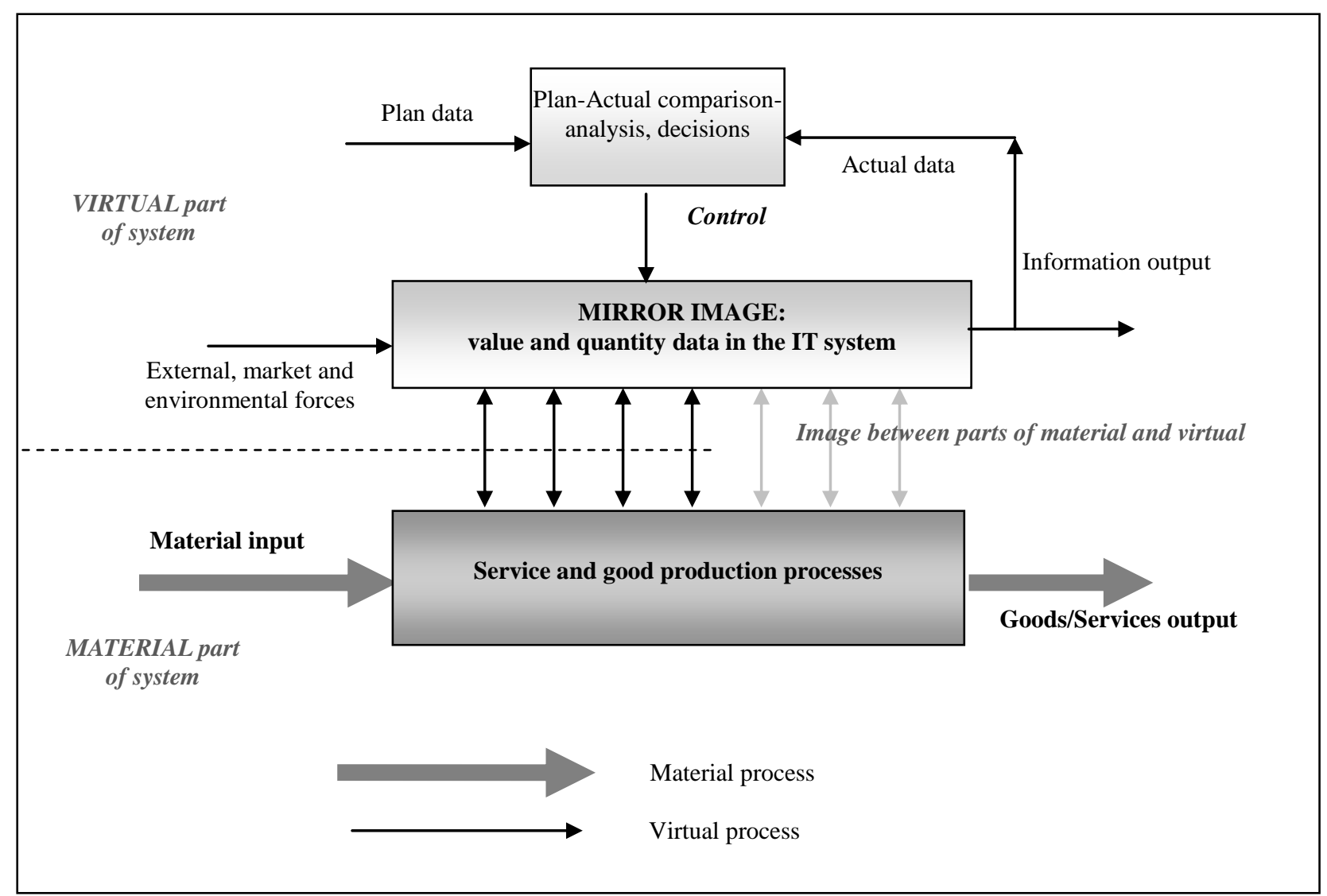

Figure 1. Cybermatics model: An IT view of controlling processes.

Legend for Figure 1:

The "VIRTUAL" and "MATERIAL" parts of the model are separated by a dashed line. The virtual part of the system is a mirror image of its counterpart - it is made up of information (data) and information processes. In an ideal case, these are accurate copies/descriptions of the actual material processes-but they are confined to the digital "realm". 
Controlling starts at planning. Planning plays a unique role in resource management adapting to the market environment. As Figure 1 focuses on processes for adaptation and self-correction, there is no room for it to describe the role of operative and strategic planning within controlling. It is necessary to return later to this issue when discussing questions of parametrization in the "perfect" business intelligence model.

During the analysis, it will be assumed that the mirror image (as described above) is indeed a perfect image of the material processes. However, it must be noted that discrepancies between the two sides of the model (imperfections) lead to regulatory issues, which hamper the enterprise's ability to adapt to the market environment. Such problems become apparent during systems checks and they must be addressed during system updates, as they impair the company's efficiency.

The whole system is controlled through the virtual side, and this process is characterized by the usual principles of Controlling: if there are discrepancies between plan and actual figures, the analysis of these differences yields information which can be used to adjust material processes towards the parameters specified in the business plans (through the two-way arrows). It can be concluded that it is actually the virtual model which embodies the business intelligence (this includes the mirror image and the regulatory systems). The referenced literature (for example Fabricius-Ferke, 2011) details the internal structure of this Controlling intelligence - it contains mostly accounting information.

External effects and information: the depiction of external information in Figure 1 is simplified, and is to be detailed later. In reality, these external effects can influence the system not just through the regulatory systems, but also by changing the planning process.

\section{Controlling as a Best System for Business}

Actual data can be influenced through the system by properly defining business parameters during the planning stage. Furthermore, external effects also affect the business entity's actual performance. Therefore, plans have a very important role, as they define goals, allocate resources, and can partly offset disadvantageous external effects (Zéman, 2015).

The goal of controlling can be defined as setting a stage where optimal future plans can be derived from the comparison and analysis of plan vs. actual figures. It is easy to see that the optimal plan will be one that just matches the eventual actual figures. Deviation from the plan causes extra costs: if resources end up being superfluous, the company will incur extra costs from unnecessary labor, inventories, and capacities. If planned resources are insufficient, then overtime and unplanned inventory acquisitions will end up costing the enterprise (Fabricius-Ferke, 2011).

A good planning system is characterized by minimal differences between planned and actual figures, that is, no significant adjustments are required. Noting this statement will play an important role in the issue of the artificial intelligence.

\section{Research Methods}

\section{Observations for Developing of Firms' Information Systems}

Having researched management information systems (MIS) for 29 years, and knowing the accounting information system of 24 firms, it is clear that the unique characteristics of their information systems are the most important from a management viewpoint. Results of the research are given in Table 1 (Fabricius-Ferke, 2015): 
Table 1

These Are Some Real Life Examples of Management Information Requests (AIT: Accounting Information Technology)

\begin{tabular}{|c|c|c|c|c|c|c|c|}
\hline No. & Sign & $\begin{array}{l}\text { Fild of operation of the } \\
\text { Company }\end{array}$ & $\begin{array}{l}\text { Monitoring } \\
\text { time period }\end{array}$ & $\begin{array}{c}\text { Revenue (in } 2014 \\
\text { HUF, million) }\end{array}$ & $\begin{array}{l}\text { AIT-1 :bookkeeping } \\
\text { functions done in } \\
\text { house or outsourced? }\end{array}$ & $\begin{array}{c}\text { AIT-2 : most important } \\
\text { module of the ERP }\end{array}$ & $\begin{array}{c}\text { AIT-3 : management unique request: all are } \\
\text { VARIOUS }\end{array}$ \\
\hline 1 & $\mathrm{PaP}$ & H. Plastic products & $1987-90$ & 25805 & ERP - in-house & Production & $\begin{array}{l}\text { Division level calculation of contribution, } \\
\text { dynamic production planning }\end{array}$ \\
\hline 2 & $\mathrm{PiP}$ & Z. Plastic products & $1990-91$ & 12375 & ERP - in-house & Production & Monitoring of production waste \\
\hline 3 & HA & Metal products & $1991-93$ & 961 & Outsourcing & Financials & Financial situation (DCF) \\
\hline 4 & KT & Textil products & $1992-96$ & 7779 & ERP - in-house & Financials & $\begin{array}{l}\text { Managing the financial situation of the firm after } \\
\text { bankruptcy }\end{array}$ \\
\hline 5 & BT & $\begin{array}{l}\text { A. Trade of construction } \\
\text { materials }\end{array}$ & $1994-96$ & 6990 & ERP - in-house & Financials & Monitoring of receivables \\
\hline 6 & SZ & Diary product & 1994-95 & 4431 & ERP - in-house & Sales & Monitoring sales by market segments \\
\hline 7 & $\mathrm{PH}$ & Trade in pharmaceuticals & $1995-96$ & 30020 & ERP - in-house & Inventories & Monitoring medicine inventories by expiry \\
\hline 8 & BK & Food wholesale & 1995-97 & 5302 & ERP - in-house & Sales & $\begin{array}{l}\text { Monitoring key customers and helping to keep } \\
\text { key customers }\end{array}$ \\
\hline 9 & InterI. & $\begin{array}{c}\text { Commercial products and } \\
\text { services }\end{array}$ & $1997-2000$ & 617 & ERP - in-house & Financials & $\begin{array}{l}\text { Monitoring of Receivables to ensure good cash } \\
\text { flow }\end{array}$ \\
\hline 10 & $\mathrm{MuP}$ & Ceramic product & $1998-2000$ & 10625 & ERP - in-house & Production & Monitoring of prodution costs \\
\hline 11 & $\mathrm{MiP}$ & A. Plastic products & $1999-2001$ & 5633 & ERP - in-house & Production & $\begin{array}{l}\text { Monitoring input usage and inventories in } \\
\text { production }\end{array}$ \\
\hline 12 & MB & $\begin{array}{l}\text { B. Trade of construction } \\
\text { materials }\end{array}$ & $2000-2003$ & 415 & Outsourcing & Inventories & $\begin{array}{l}\text { Managing stockpiles in accordance with } \\
\text { customers' needs }\end{array}$ \\
\hline 13 & OST & S. Industrial services & $2000-2001$ & 409 & Outsourcing & Inventories & Managing inventories, utilizing old stocks \\
\hline 14 & TK & $\begin{array}{l}\text { C. Trade of construction } \\
\text { materials } \\
\end{array}$ & 2001-2010 & 15956 & ERP - in-house & Financials & $\begin{array}{c}\text { Monitoring customer credit limits (taking unpaid } \\
\text { obligations into consideration) } \\
\end{array}$ \\
\hline 15 & $\mathrm{KO}$ & B. Plastic products & $2003-2004$ & 433 & Outsourcing & Production & Labor utilization \\
\hline 16 & $\mathrm{BF}$ & A. Industrial services & $2001-2002$ & 265 & Outsourcing & Inventories & Availability of goods stockpiles \\
\hline 17 & EV & Civil services & $2003-2013$ & 1250 & ERP - in-house & Industrial services & Costs of municipal services \\
\hline 18 & $\mathrm{TT}$ & $\begin{array}{l}\text { D. Trade of construction } \\
\text { materials }\end{array}$ & $2007-2009$ & 4228 & ERP - in-house & Sales & Sales margin of different products \\
\hline 19 & BH & B. Industrial services & $2007-2015$ & 680 & Outsourcing & Industrial services & $\begin{array}{l}\text { Accounting the amortization of machinery that is } \\
\text { currently under-utilized (kept for spare capacity) }\end{array}$ \\
\hline 20 & AT & Sped services & 2010-2011 & 869 & Outsourcing & Industrial services & $\begin{array}{l}\text { Project level and transport vehicle level } \\
\text { profitability }\end{array}$ \\
\hline 21 & DPA & Car services & $2009-2011$ & 311 & Outsourcing & Industrial services & $\begin{array}{c}\text { Calculating the contribution of different } \\
\text { operations }\end{array}$ \\
\hline 22 & $\mathrm{CA}$ & Food products & $2012-2014$ & 838 & Outsourcing & Production & Separating fixed and variable costs in production \\
\hline 23 & $\mathrm{AG}$ & Car component products & $2014-2015$ & 31715 & ERP - in-house & Production & TQM statistis of production machinery \\
\hline 24 & $\mathrm{CO}$ & C. Plastic products & 2014-2015 & 17500 & ERP - in-house & Production & $\begin{array}{l}\text { Calculating special production costs in case of } \\
\text { continuous cost-cutting }\end{array}$ \\
\hline
\end{tabular}

Colors of the 1st table have meaning as follows:

In the 4th column, AIT-1: this is the basic method of bookkeeping and preparing annual reports. You can only see two cases in this column: bookkeeping by outsourcing or by an in-house ERP system.

In the 5th column, AIT-2: this column shows the most important parts of the companies' ERP systems (which are related to the areas that determine the firms' success). The 24 companies can be put into five categories.

The 6th column is AIT-3, which contains the most important information requests of the management (at the moment). This information requests the unique and special demand of the management. 
About AIT-3, it can be said that there are three general cases when AIT-3 solutions are needed.

The ERP system cannot answer the management's unique (data) requests. In this case, it is necessary to design a new subsystem.

A new ERP system is introduced, but it cannot provide the appropriate data, or that data are wrong. In this case it is necessary to modify the system.

The management's information needs change faster than the how the ERP system can be updated.

\section{Rate of AIT in Economy (AIT 1, 2,3)}

It should not be surprising that enterprise ERP systems do not give all-in-one solutions for accounting needs. This is due to two simultaneous factors:

Among the different accounting issues, financial accounting needs are relatively easy to define and do not differ much across companies. However, management accounting needs are always company specific, as they depend on the given enterprise's unique characteristics and environment. More specifically, management accounting needs depend on:

- the company's operations, including its CSR policies;

- its ownership structure;

- the company's direct partners and its position in the supply chain;

- the market environment, competitive conditions, and macroeconomic forces;

- leadership and organizational characteristics.

Essentially, a company's accounting needs depend on every element of the BSC model (Kaplan \& Norton, 1992), although the weighting of these factors will differ across different enterprises (due to their unique characteristics). The stipulation that managerial accounting strongly company specific is well supported in the literature (Böcskei, 2014; Böcskei, Fenyves, Zsidó, \& Bács, 2015; Horgren, Sundem, \& Straton, 2008; Horváth \& Partner, 2001; Körmendi, 2002; Sinkovics, 2010). Also noting that the strategic controlling issues highlighted by the A. Rappaport's VBM (Value Based Management) approach are also highly company-specific, which was promoted by Rappaport (1986).

The mirror image in the virtual part of the "Cybermatic" model (see Figure 1) must be very accurate in order for Controlling to be effective. This means that the integrated IT systems of enterprises also differ from company to company, as they must be able to properly support the service or manufacturing processes of that specific entity (Fabricius-Ferke, 2014).

The results of the research presented in clearly show that purchased ERP systems were only partly able to create a proper mirror image of the companies' processes. The establishment of well performing systems required the creation of business intelligence (BI) sub-systems that served the companies' unique management needs (this is AIT-3).

It is important to note that these subsystems (AIT-3) that are developed on a case-by-case basis are actually the ones that are the most important in terms of the company's profitability (Ferke, 2011).

\section{The Significance of Data-Structure}

If planning within the system works well, that is, the system is enabling good business performance without frequent and significant deviations from planned figures, then the accounting system in question achieves its goals. This also means that the changing management information needs are gradually built into the accounting system and the management receives proper information for decision making. Due to this 
internal development process, business planning and operations will be able to adapt to market conditions and other external factors (exchange rate fluctuations, changes in regulatory environment, etc.) more easily. It should be noted however that this development, or in other words adaptation, is not monotonic, as significant internal or external shocks (e.g. the Great Recession) may still cause temporary regression of adaptive capability.

At the same time, it is certain that outcomes of the development process are integrated into the ERP system - that is, into the virtual mirror image that performs the regulation. It is clear from the information systems literature that this sort of development can be modeled as an endless circular process. The following is known about information systems:

The software and the data within can be developed and changed more or less independently from each other, while at the same time, they form a dynamic relationship with each other (Neumann, 1959).

A prerequisite for software to work is for them to be compatible with the data structure (McGrow, 1993). It is necessary to record data and any set of commands (as a software) within the memory (Neumann, 1959), and through the recorded commands, the building blocks of the "intelligence" get recorded in the memory. Recent advancements in technology have led to a surge in the availability of memory and therefore this is no longer a barrier to the development of BI systems.

Three conditions must be met for new types of management information reports to be available from the accounting system:

- A data structure that is compatible with the new type of request.

- A software that has been modified to be able to handle the request.

- The necessary input data have already been recorded or supplied through the OLTP (online transaction processing) system (McGrow, 1993; Fabricius-Ferke, 2011).

And furthermore: As it was noted before, the information system enables the planning and controlling of business activities. It does this through supporting decision making with information, but crucially, the set of queries that provide this information is always changing, albeit gradually.

With every upgrade, new types of queries become possible while old ones are phased out. This happens in tandem with changes in the data structure, but this needs to be apparent to the user.

The best way to imagine what the data structure looks like might be to think of it as a collection of files, which is technically a collection a of data tables. There are "ID" variables (columns) in each data table which allows one to link the data from different tables together. The software works using these data links to retrieve information from the different tables.

In conclusion, it can be said that the development of the ERP system is "stored" in the changing data structure. The system evolves such that the data structure will allow more and more sophisticated and flexible business planning and controlling. This essentially means the evolution of the business intelligence (BI). It should also be noted that software changes along with the data structure, and the amount of data stored in the system may also change.

\section{Research Results}

\section{Evolution}

Table 1 gives a few examples of how ERP systems are developed and adapted to fit the external environment of the firm. 
- 4th row (Textile Products): financing production with loans, then analysis of receivables, then management of bankruptcy proceedings.

- 14th row (C. Trade Construction Materials): billing, then receivables management, then centralization of procurement.

- 17th row (Civil Services): management of current expenses and production overheads, then calculation of project costs, then analysis of overheads.

- 19th row (B. Industrial Services): personnel cost reporting, then amortization accounting, then calculation of project costs, then value-added type cost analyses.

- 22nd row (Food Products): cost analyses, then ISO type quality-management system.

After solving one task, the next one follows, and management can prioritize between them. These procedures are made possible by the development of the ERP systems that encompass the controlling systems.

In the following section, some characteristics of ERP systems will be compared to that of natural systems, from a systems theory viewpoint. One can look at some-somewhat arbitrarily - chosen characteristics from Darwin's (Darwin, 1859) to look at how the two systems compare in terms of evolution:

Both systems are complex, with intricate structures and systems of interrelations between elements.

An important similarity is that evolution of the system comes from the pressure to adapt. Natural systems adapt to each other and the larger systems that surround them. This is mimicked by ERP systems, which adapt to competitive pressures and the market environment.

Due to the above, it is true in case ERP and natural systems both that successful adaptation means survival and proliferation, while unsuccessful adaptation leads to disappearance.

There are many factors that drive the functioning of both systems, and a majority of these cannot be measured. In the case of ERP systems, this can be seen that it is not possible to track and measure all of the parameters that characterize the real life environment that serves as the basis of the virtual mirror image. Even if measuring them were possible, it would certainly not be profitable.

There are also differences between ERP and natural systems which will be important for the analysis:

The characteristics or parameters of natural systems are much more difficult to identify, interpret and model than in the case of ERP systems. An example of these gene mutations: at first glance, these seem not to be useful, whereas it is known that they help in the adaptation and survival described above.

It is also an important difference that there are no plans or a planner in natural systems (one that would compare plans and outcomes). Some critics of Darwin do not agree with this statement, but this analysis will stick with this "simplification" for now. One could revisit this question, and debate whether there is some higher form of control hat influences natural systems, it will be shown that from the perspective of this specific topic, this question is irrelevant.

\section{Integrated IT Systems}

Some common and important characteristics of integrated systems have to be mentioned. For an integrated system to potentially provide the basis of the perfect business intelligence, it must satisfy the following criteria (Fabricius-Ferke, 2011):

- It should not have data redundancies, only inasmuch as required by that specific business area in which it operates (Ferke, 2012a);

- It should not have parallel (redundant) processes or queries (save for the necessary minimum level); 
- It should operate as an online application; and wherever profitability or necessity considerations allow, should operate in real-time.

Most of the software systems used by business entities are integrated systems. This implies the three points above and the fact that the modules of these systems are accessible through a single application. All the data used by these systems are also stored centrally in one location. However, they differ in terms of the method of data processing (computer data processing and manual data processing). But, as it has been have established before, the BI integrated into the software and the data structure is constantly evolving due to external effects, and therefore the share of manual and computer processing also changes. For example, new types of report required by the management first become available offline. They are found in the OLAP system in data mining format, and over time, as the exact expectations about the report become clear, they get integrated into IT system, thus becoming a part of the BI. Therefore, the picture of all data processing activities in the firm looks like this: It has two parts, a computerized/BI part, and a manual part of the system (see Figure 2) (based on Fabricius-Ferke, 2011):

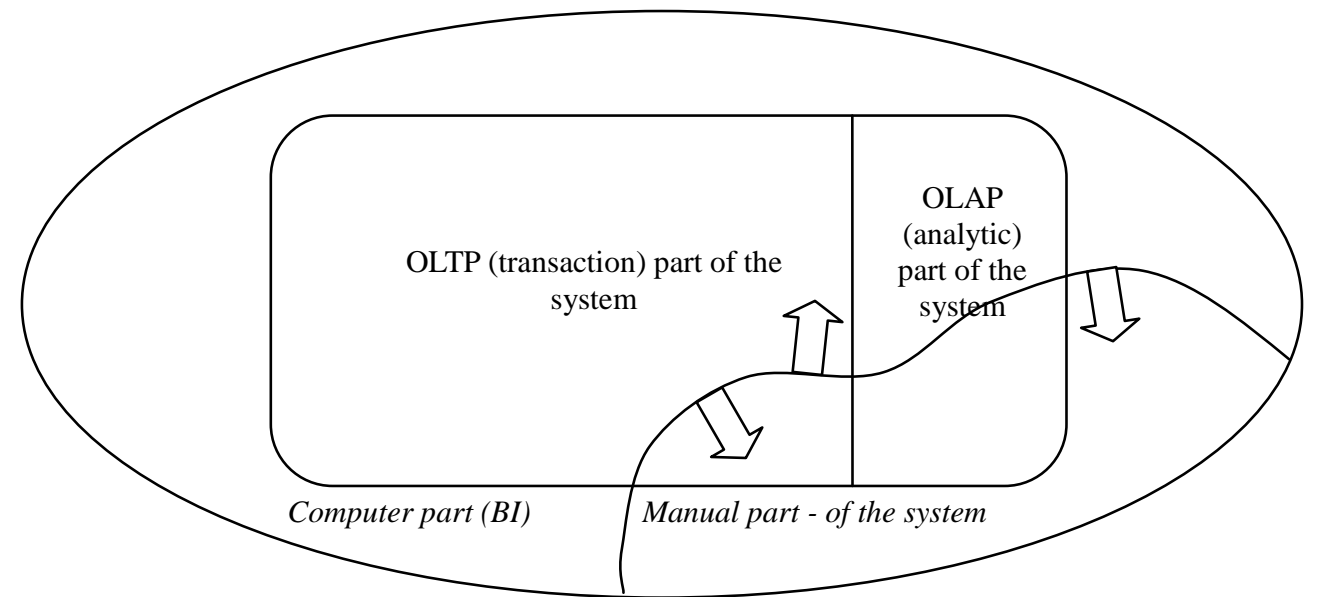

Figure 2. Due to adaptation to the market environment, the share of BI processes within the entire ERP system changes.

\section{Discussion}

In the following section, the upper part of the Figure 1 will be discussed; that is, the virtual part of the system, as this is the part that contains the elements of the business intelligence that make up the Controlling system. The interaction between these elements is where one can hope to find the potential for a perfect BI. Based on all the above sections and Table 1, one can outline what the elements of a realized BI would look like. The conclusions one arrives at can be guidance in ERP systems development, as they identify the characteristics, one must work towards to create a perfect BI.

\section{What Are the Characteristics of a Good ERP System?}

About elements of business intelligence in IT: When purchasing ERP systems, only the common elements of the BI can be acquired; the elements that are required to support the company's unique needs must be developed by the economic entity itself. As detailed above, AIT-1 technology can be purchased along with the software; AIT-2 technology can be purchased but needs to be implemented; while AIT-3 technology must be developed by the entity itself. The difficulty is that in the meantime, the system must be integrated. Concisely, a 
good ERP system must have mixed technology: partly purchased, partly self-developed. This means that the integrated BI systems used at different companies (and especially the modules that are the most important from a profitability viewpoint) will not be identical, and therefore cannot be mass-produced.

On the long term, the development of the intelligence system will be discontinuous (Fabricius-Ferke \& Zéman, 2016). This is because in case of larger systems, the basic changes outlined in the company's IT strategy can and should only be implemented into the information systems once every few years. Based on the rules of systems development (McGrow, 1993) and practical experience (Table 1), this time period varies from two to five years and depends on the size of the company. Based on Table 1, here are some practical examples of when intervention in the form of significant changes to the software and data structure was necessary in order to improve profitability:

- H. Plastic products: introduction of daily division level production reports, 1988;

- Z. Plastic products: introduction of a quality-tracking system based on item-level weight measurements, using industrial interfaces, 1991;

- Metal products: introduction of a strict cost management system, made necessary by bad financial situation, 1993;

- C. Trade of construction materials: weekly reports and analysis on receivables, 2005; introduction of a centralized good procurement system, 2008;

- Food products: Introduction of a cost management system specifically related to the costs incurred by central operations, 2012;

- B. Industrial services: Introduction of accurate personal costs analysis, 2009; changing the accounting practices related to amortization, 2013;

- ...the list of examples could be continued...

As shown in Figure 2, new types of report required by the management are initially generated manually, (i.e. they are not part of the integrated system). They are found in the OLAP system in data mining format, and over time, as the exact expectations about the report become clear, they get integrated into IT system and the data structure, thus becoming a part of the BI.

It can be concluded that the six examples above also support the "our" statements: Controlling systems require unique IT solutions. The unique solutions were all aimed at carrying out company-specific reporting tasks that were integral elements of their resource planning activities. Consequently, every single BI created as such was unique and company-specific.

An additional result is that the evolution of BI systems is discontinuous, which sets them apart from the continuous Darwinian natural evolutionary processes. However, one can also conclude that the "intellectual capabilities" of BI systems evolve and expand just as those of natural species.

\section{Planning and Chance in Enterprise Management Systems}

After having presented how, in an optimal case, BI systems should be acquired and developed, one should turn their attention to external factors. At the development level where modern companies are, competitive forces are a determining factor in how companies are managed. Competitive forces will always have significant effects, but how they impact companies depends on two factors: planning and chance.

The ambiguous role of planning: to present the connection between planning and chance, this analysis will compare the microeconomic role of planning in developed countries against that in the ones that became market 
economies after 1980-1990:

- In developed market economies, microeconomic entities (companies) have been engaging planning for a long time. In their case, the discourse is on whether and exactly how macro considerations should enter the planning/controlling process of small entities.

- In the countries that became market economies in the 80's and 90's, microeconomic planning has a more complicated history. The main problem of the former state-socialist "communist" era is that micro-level planning was entirely absent before the 80 's. This situation was also exacerbated by the existence of state planning, where they attempted to have everything (including the operation of micro-entities) planned out centrally by the state - even though this was incompatible with the level of economic development these countries had already reached. In some countries, the situation has not improved much.

When designing the BI systems of business entities, it is very important to select the right planning parameters along which a controlling system will operate. This may be made difficult by the need to include controversial things in the planning system or the out-of-date macro regulations which have to be implemented into micro systems and which inhibit efficient responses to market forces.

Chance and other inhibiting factors: In the "controlling as a feedback system" section and Figure 1 some external market forces have been mentioned. These can be characterized as follows:

- There are market forces from the direction of competitors, suppliers, buyers and investors.

- There are other chance factors which affect the regulatory system, called "chance factors" or "inhibiting factors". They are not foreseeable within the market, and are difficult to model with mathematical or statistical methods. In a mathematical vernacular, these factors cannot be modeled with the use of market parameters, so they must be regarded as random. From the viewpoint of BI development, out-of-date macro requirements are categorized as such inhibiting factors. This is also the reason why in "Research result" section we stated that the existence of a planner or higher power is irrelevant to the topic of BI systems, as these would also fall into this category.

Two examples of the controversial nature of implementing plans into the regulatory system based on Table 1:

- In the 1990's, ceramics production activities received certain tax exemptions in the Hungarian tax code. The owners of the "Ceramic product" company realized the opportunity that this presented and included these effects in their production and sales plans. This led to such high profits that the company was able to amass significant real-estate wealth over eight years.

- At the beginning of the 2010's, laws were passed in Hungary which restrict the production and sales of alcohol and tobacco products. The "Food products" small enterprise was forced to implement these new regulations into its management systems, and as a consequence, it has effectively gone bankrupt.

To summarize the topics raised above, it can be said that to create a well-functioning BI, the following is required:

- Planning must accommodate for the presence of market forces as much as possible, even though they will not be the only influencing factors (due to the ones we mention below)

- One must decide which environmental factors will be given the most consideration, and implement modules into the planning system that allows one to deal with these, and:

- Remembering that there are "random" effects, which cannot be planned for but will influence the performance of the Controlling system. 


\section{The Perfect Artificial Intelligence}

This part of the analysis moves from the Controlling system based examples to a more general definition of the perfect artificial intelligence. Note that the parallel between BI and natural systems will continue to be used. Furthermore, in this topic, information generated internally and that gathered from external effects will play a defining role.

A basic issue when talking about "intelligence" is whether it is capable of improving itself on its own, within the confines of the system? Can the intelligence figure out how to handle new variables and new external factors, and whether to integrate those into the planning system? Succinctly, can it adapt to its environment on its own?

The issue of relative complexity: it is important to note that the systems used to manage companies - similarly to natural and social systems - are complex. This means that the data they handle have large volume and have a complicated structure. These factors influence how the perfect intelligence should be developed:

The relative complexity (in terms of volume and structure) means that there are many processes in the system that is relatively unknown, unregulated. The processes and the relationship between them are difficult to fully understand. This phenomenon is similar to that of gene variations in natural systems, where you will have variations that are present and inactive, but may become relevant in the future.

Somewhat paradoxically, these apparently redundant functions may provide stability. This means that changing a few parameters will not fundamentally alter the functioning of the system, as there are numerous other, presently inactive functions that matter. An example: one uses several different indicators in controlling systems. These indicators are calculated values which will be used in the next period of planning as parameters, and will thus affect the system. If an indicator changes, one can track the further variances in it and see if it affects anything else in the system. If it doesn't, it can be concluded that the change was just incidental.

Therefore, the relative complexity leads to some degree of opacity in terms of details but also stability.

The operative part of the system embodying the perfect artificial intelligence: this part of the system differs from Controlling in that to model external effects/influences, one needs to use random variables as input data (Figure 3). These variables may operate as targets to which the company has to adapt, even though it cannot affect these targets (as opposed to operational plans). In business applications, these system parameters relate to the company and the market, but in case of other intelligence system, this will be different.

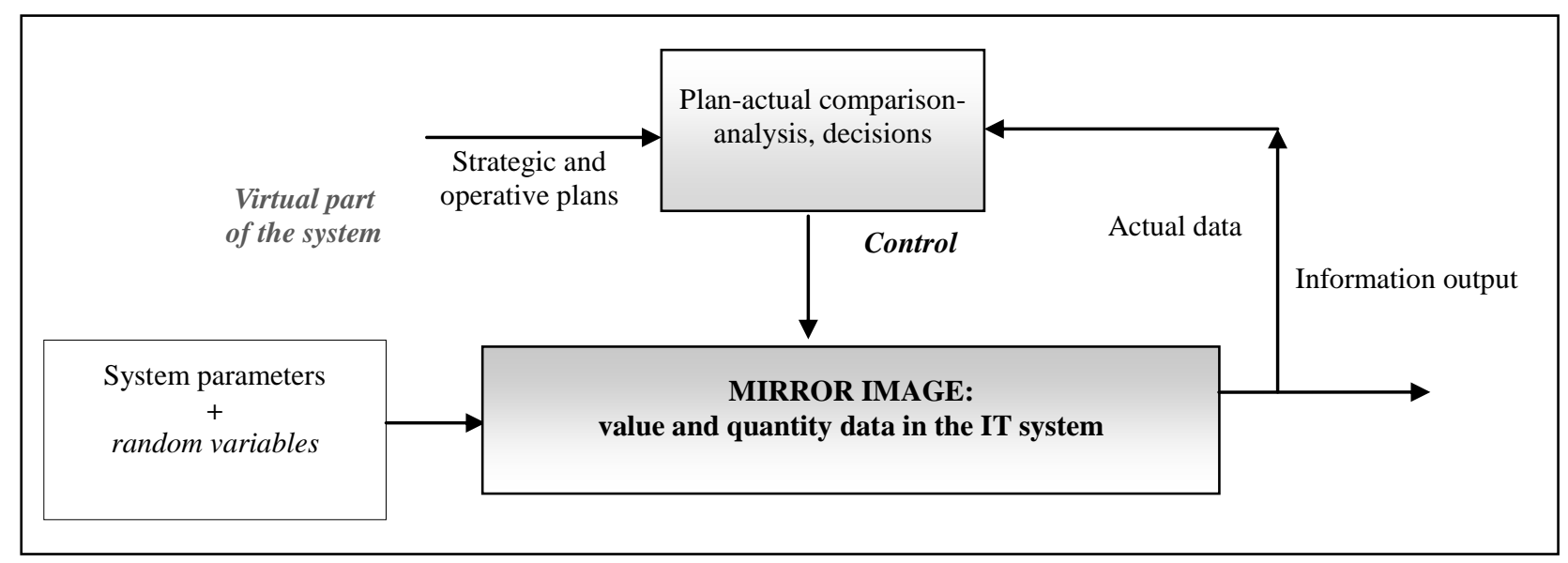

Figure 3. A solution outline to a potential artificial intelligence (Fabricius-Ferke, 2011; 2014). 
Random variables are ones that cannot be modeled using the parameters of the system or the environment (such as an accident, or a personally motivated macroeconomic decision). The company has to treat this kind of input data as operational goals even though it cannot affect them. These data go through the operative regulatory part of the system and produce results that do not instantly cause a regulatory response. The following factors can help with adapting to these random variables:

There are redundant modules and parameter variations available from which the system will select the ones that are the most appropriate for the planning goals in question. This is necessary because the system will not be able to give an appropriate regulatory response to these random variables using the standard planning variables along which it operates, as these are developed to give information about the market, and cannot account for such random, unplannable inputs.

Along these "redundant" modules and parameters selected, the system will be relatively efficient in performing its usual regulatory function.

Adaptation/evolution comes from the adaptation to the random factors described above. This part of the system is similar to natural evolution. A key point in the evolution of natural species is that the random factors lead to random changes in internal parameters (gene variants), which, in the long term, leads to adaptation to the environment and selective pressure. This process is important from the viewpoint of the perfect artificial intelligence model as well.

Among the factors influencing the system, we can find "supernatural" ones as well. As previously mentioned, these can be treated as factors that cannot be modeled. However, as it will be shown, they might be considered during strategic planning.

The role of strategic controlling figures, as initial "parameters". Figure 3 presented a distinction between strategic and operative planning. In the perfect artificial intelligence system, one exercise control through the parameters of our strategic plans. Given the random variables discussed, the adaptive processes in the operative system should be allowed to function relatively freely. It's the long term strategic plans that one can use to influence the system in the desired direction right at the beginning of its operation. If the regulation of the system becomes more efficient (there are only small adjustments required period to period, as discussed in Section 2), then one can allow the system to operate on its own for longer period of time. Stretching this time period between strategic "interventions" is how we gradually move towards a perfect artificial intelligence.

\section{Conclusions}

The importance of this study is the next: in the case of a limited and allotted system, the requirements/approaches to create the perfect business intelligence are as follows:

- Start from a Controlling system and use the strategic and operative planning modules of the system.

- Operative functions: On top of the known and closely managed modules, parameters and variables in the model, there are also informal, "random" functions and variables. One should be aware of their existence, as they help the system's adaptive processes, but one should try to limit their influence so as to keep operative processes running smoothly.

- Data gathered from the firm's environment give one information about how well the system is functioning and what adaptations are needed. However, there is also informational "noise", the effects of which should be mitigated. But at the same time, as before, one must acknowledge their existence, as they might be helpful when the need to adapt the system arises. 
- Therefore, in case of a specific controlling system, the perfect artificial intelligence should be achieved by gradually lengthening the strategic planning cycles, this produces a development path in which over a long time, the system asymptotically approaches the state of being a perfect BI.

- One must recognize that artificial intelligence developed for unlike purposes will be unique in that sense that they will not be universally applicable.

\section{References}

Bertalanffy, L. (1962). General system theory-A critical review. General Systems, 7, 1-20.

Böcskei, E. (2014). The accounting policies came to the fore-The information content of internal accounting, as the basis for management accounting. Controller Info, 2, 38-43.

Böcskei, E., Fenyves, V., Zsidó, E., \& Bács, Z. (2015). Expected risk assessment-Annual report versus social responsibility. Sustainability, 7(8), 9960-9972.

Darwin, C. (2001). The origin of species by means of natural selection. Budapest, HU: Typotex (Original work published: 1859).

Fabricius-Ferke, G. (2011). IT for controlling \& managerial accounting. Budapest, HU: CompLex Press Ltd.

Fabricius-Ferke, G. (2014). Cybermatic. Controller Info, 2, 6-11; 4, 46-48.

Fabricius-Ferke, G. (2015). How to improve your ERP system-A 3.M theory. 8th International Scientific Conference "Challenges in Economic and Technological Development”. Lillafüred, HU, 15-16 October, 2015.

Fabricius-Ferke, G., \& Zéman Z. (2016). "Certain information technology aspects of Controlling Mega Trends” (Part 1). Controller Info, Budapest, 3, 10-14.

Ferke, G. (2011). Who is the owner of the business IT? Controller. Ecovit Ltd, then CompLex, Budapest. 2011: 7-8, 5-15; 9, 10-12; $10,9-12 ; 11,8-12 ; 12,10-12 ; 2012: 1,6-10$

Ferke, G. (2012a). Controlling versus business, managerial accounting, financial accounting. Controller, CompLex. 2012: 4, 8-14; 5, 14-21; 6-7, 22-28.

Ferke, G. (2012b). The over-reliance on computers. Controller. CompLex, Budapest. 9, 320-324.

Horngren, C. T., Sundem, G. L., \& Straton, W. O. (2008). Introduction to management accounting. New York, NY: A Pearson Education Company.

Horváth \& Partner. (2001). Controlling - The way to an efficient controlling system. Budapest, HU: KJK Judiciary \& Business Press Ltd.

Kaplan, R. S., \& Norton, D. P. (1992). The balanced scorecard: measures that drive performance. Harvard Business Review, 1-2, 71-80.

Körmendi, L., \& Tóth, A. (2002). Scientific approach to controlling and its application. Budapest, HU: Perfekt Press Ltd.

McGrow \& Hill. (1993). Software system development. New York, NY: The McGrow-Hill Companies.

Neumann, J. (1959). The computer and the brain. York, PA: Yale University Press, Maple Press Company.

Rappaport, A. (1986). Creating shareholder value: The new standard for business performance. New York, NY: Free Press.

Sinkovics, A. (2010). Corporate financial planning. Budapest, HU: CompLex Press Ltd.

Zéman, Z. (2015). The effects of mega-trends on the building blocks of controlling vs. the perspectives of controlling. Conference: Challenges and Lessons in the Field of Management. University of Debrecen, HU: 08-09 October, 2015. 